\title{
Continuing Challenges in Transportation Adaptation
}

\author{
Michael J. Savonis • Joanne R. Potter • Cassandra B. Snow
}

Published online: 31 January 2014

(C) Springer International Publishing AG 2014

\begin{abstract}
The serious assessment of climate change impacts on transportation is just six years old. Yet considerable progress has been made in this short time. Analytical frameworks to couple decision support for transportation decision makers at the national, regional, and local levels with the leading edge of climate science have been established and tested. A better understanding of the risks and vulnerabilities facing transportation agencies has been accomplished through a growing number of assessments. But significant gaps exist, and the full integration of climate impacts in transportation planning, design, and operations has yet to be accomplished. Adaptation planning and implementation lag except where disasters have struck. Research must play a critical role over the next decade to address societal impacts, better define critical concepts and make them useful for practitioners, and integrate climate concerns more completely in the natural and built environments across all sectors, including transportation.
\end{abstract}

Keywords Adaptation $\cdot$ Climate change $\cdot$ Extreme weather events · Vulnerability · Impacts · Adaptive capacity · Adaptive management · Transportation · Asset management · Operations · Maintenance $\cdot$ Design

\section{Introduction}

Upon the 2009 release of Global Climate Change Impacts in the United States [1], then-Administrator of the National

\author{
M. J. Savonis $(\varangle) \cdot$ J. R. Potter $\cdot$ C. B. Snow \\ ICF International, 1725 Eye Street NW, Suite 1000, Washington, \\ DC 20006, USA \\ e-mail: Michael.Savonis@icfi.com \\ J. R. Potter \\ e-mail: Joanne.Potter@icfi.com \\ C. B. Snow \\ e-mail: Cassandra.Snow@icfi.com
}

Oceanic and Atmospheric Administration (NOAA), Jane Lubchenko, called it a "game-changer." She felt that the impacts of climate change were so clear and potentially devastating that the need to address them in all sectors, including transportation, was obvious. This report and two others in 2008, the Potential Impacts of Climate Change on U.S. Transportation [2] and the Gulf Coast Study: Phase I [3], essentially marked the beginning of the modern study of transportation vulnerabilities to climate impacts. In the intervening six years, research and assessment reports on the topic have expanded exponentially [4], but progress has not been uniform across the different analytic areas that are required to fully integrate climate considerations into transportation practice.

Vulnerability assessments at the facility, network, and national levels have been conducted, which describe in greater or lesser detail, the challenge that climate change poses to transportation. Most frequently, climate vulnerabilities and impacts are being analyzed at the facility level, such as a port or a road segment, for example. Less frequently are impacts analyzed at the network level, taking into account the interconnected nature of an intermodal system, regionally and nationally. Even more rarely are the societal impacts caused by the loss of transportation service considered, leaving an incomplete picture of climate disruption. Societal impacts must be more fully incorporated into vulnerability assessments.

Important progress has been made. Analytical frameworks have been developed and deployed that attempt to marry the needs of transportation practitioners with the data and analysis of climate scientists. The impacts of climate on infrastructure and operations are increasingly examined and understood. Framework development is still very much a work in progress, however [5], and fundamental concepts in climate assessment still need to be defined and operationalized for transportation and other infrastructure systems.

Adaptation action in response to a greater understanding of climate risk, however, has not kept pace. The strides that have been made in vulnerability assessment have not, as yet, been 
matched by effective adaptation planning and implementation. Climate impacts are being realized at all levels of transportation decision-making, including the design and siting of facilities, as well as in operations and maintenance (O\&M). Adjustments to O\&M have been made as necessary, but there has been a reluctance to take more significant measures - such as changing locations and designs - based on existing climate information. Methods for evaluation of competing adaptation measures, including not only their costs and benefits, but also their effectiveness in addressing climate impacts, remain a much-needed frontier for future development. Further, implementation of adaptation measures typically lags far behind. While disasters such as "superstorm" Sandy, Mississippi flooding, and extreme heat events have galvanized action in locations that have been struck by these events, those areas that have not experienced such disasters remain relatively complacent about taking pre-emptive adaptation action. Analysis and continued creativity — on the part of both researchers and practitioners - are vitally needed to provide the data, tools, and approaches needed to establish more robust and resilient transportation services that will withstand changing climate conditions.

Adaptive management has not been fully adopted by the transportation sector, but efforts are underway that are likely to yield crucial advances. Adaptive management is a continuous process of analyzing climate impacts, monitoring them as they occur, making adjustments as necessary through adaptation, and evaluating the effectiveness of those adjustments. It supports maximum flexibility in adaptation responses to allow for climate uncertainties, as well as integration of climate factors into an agency's ongoing performance evaluation process. Although hurdles remain to the adoption of adaptive management techniques, significant advances in examining the impacts of extreme weather events through comprehensive asset management approaches are in process.

The following sections discuss the state of practice and future challenges in each of these analytical areas, first addressing vulnerability assessment, then adaptation planning, and then discussing how these processes can be integrated through an adaptive management approach.

\section{Vulnerability Assessments}

Bringing long-term climate projections to the very practical levels needed by transportation practitioners focused on service decisions requires merging two vastly different paradigms. The development of some analytical frameworks to facilitate this has been a critical first step. Much progress has been made in adapting the science-focused climate change frameworks from the IPCC for use in vulnerability assessments conducted by governments and infrastructure managers, but important elements are still missing. A critical conceptual element of vulnerability - that of adaptive capacity - has not been clearly developed for the built environment. New approaches have been developed to better manage assets, but climate change and extreme weather events have yet to be fully incorporated into them. Finally, the societal implications of climate change stemming from the loss of vital infrastructure services have yet to be fully described.

\section{Framework Development}

Vulnerability assessment frameworks for transportation facilities are becoming more common. Assessments of ports [6], transit [7•], freight lines [8], and airports [9] have been done across the globe using a variety of frameworks, including qualitative scoring approaches that rank risks based on their consequences and probabilities, as well as more quantitative approaches. A particularly comprehensive summary of climate impacts on ports and sea trade was published by the U.N. in 2012 [10].

In the USA, the Federal Highway Administration (FHWA) has led the effort to develop frameworks and support peer exchange opportunities among State Departments of Transportation (DOTs) and Metropolitan Planning Organizations (MPOs). FHWA published a vulnerability assessment framework in December 2012 based on experiences of five pilot projects. As concern among transportation agencies about climate impacts has risen, a growing number of agencies are drawing on such tools; at least 23 State DOTs have used or are using the FHWA framework to assess their vulnerability and begin adaptation planning. The exact approach used by different agencies to assess vulnerability varies - ranging from data-driven desk analyses to facilitated workshops with stakeholders - but they each result in an understanding of vulnerabilities and information that can be used to prioritize more targeted risk or adaptation assessments. The FHWA vulnerability assessment framework is being further tested and refined through 19 "climate resilience pilot projects," with seven focused exclusively on vulnerability assessments [11]. While numerous approaches have been used, not all of them are of comparable rigor. Data and resource limitations and an incomplete understanding of the magnitude of the climate challenge have often left transportation agencies with a general notion that risks exist, but questions of how big that risk is and how to minimize it are often left unanswered. The variety of frameworks that are now employed calls out for an assessment of best practices and greater standardization across approaches.

The interaction between natural environment systems and infrastructure systems - including transportation - adds further complexity to the task of vulnerability assessment. For example, climate impacts on the hydrologic cycle and aquatic systems have particularly profound implications for infrastructure services. As sea levels rise, barrier islands and marshes that have provided protective buffers disappear; 
patterns of flooding, soil accretion, and vegetation evolve; and the assumptions underlying the siting, design, and maintenance of transportation infrastructure must be reexamined. In turn, the environmental impact of transportation measures likewise needs to be reassessed in light of different potential climate scenarios. Wetland mitigation measures, for example, need to incorporate future climate projections to ensure the long-term viability of mitigation investments [3]. Road alignments that were historically considered to have no impact may now exacerbate flooding during severe storm events due to changing sea levels and evolving land uses.

While there is substantial literature on climate change, there remains an urgent need for more information specific to the impacts of climate change on transportation to inform practitioners as they make decisions about priority investments. Recent advances have included a greater emphasis on forecasting of extreme heat and precipitation events - climate stressors that tend to have more significant impact on transportation systems. Rowan et al., have developed a sensitivity matrix tool to help transportation decision makers assess the relative sensitivity of transportation infrastructure to climate impacts, with a focus on severe events. This sensitivity matrix, developed for the FHWA as part of a case study of transportation assets in Mobile, Alabama, helps transportation managers identify those assets and services at greatest risk to damage and disruption due to climate change, so that they can direct adaptation measures accordingly [12]. Dobbins and Abkowitz are developing a decision framework for transportation managers based on impact thresholds to infrastructure and corresponding potential adaptation measures [13]. As transportation practitioners increasingly interact with climate and environmental scientists, more detailed data and relevant analyses can be expected.

\section{Adaptive Capacity}

Vulnerability to climate stressors is intuitively understood by most practitioners, however the underlying analytic components of vulnerability - exposure, sensitivity, and adaptive capacity — are less familiar. Further, these concepts were first developed by scientists with natural systems in mind. Application to the built environment has not been fully realized. The exposure and sensitivity of an asset to climate stressors are perhaps more easily understood, although in practice the interpretation of these concepts can be confusing; for example, if an asset experiences storm winds that are below its design threshold, is it not exposed or merely insensitive to a climate stressor [14]? Of more concern is how the concept of adaptive capacity applies to infrastructure. Far from a theoretical exercise, the identification of a system's adaptive capacity can provide a more accurate indication of the service levels possible during and after extreme weather events (EWEs).
Understanding a system's adaptive capacity is, thus, an important part of the framework for adaptation planning.

Recent attempts to define adaptive capacity have more intuitive appeal than the formal IPCC definition, which defines adaptive capacity as "the ability of a system to adjust to climate change (including climate variability and extremes) to moderate potential damages, to take advantage of opportunities, or to cope with the consequences" [15]. More practitioner-focused definitions of adaptive capacity emphasize the ability to maintain service through system redundancy and the time it takes to return to full service levels following a EWE [14].

These efforts to reframe the concept of adaptive capacity are welcome advances, but incomplete. Still to be determined is what capacity it takes to return damaged or destroyed assets to full service levels. Questions such as budget, institutional capacity, technical expertise, and the ability to identify and mobilize funding from multiple sources have yet to be considered in a comprehensive framework of adaptive capacity and resilience.

\section{Societal Impacts}

When considering the implications of climate change, the first instinct of transportation managers likely is to focus on the direct impacts of climate on the condition of specific infrastructure and facilities. How, for example, may changes in climate affect a particular highway or bridge structure? Yet a broader assessment of how climate stressors affect transportation systems - and in turn, affect communities and economies - is essential to achieving the most effective and sustainable strategies. As expressed in a 2012 technical report supporting the U. S. National Climate Assessment, "Although considerations of infrastructure often seem totally concentrated on physical structures, those structures are especially important because they are means to social ends. In other words, services and not structures are what are important to users and decision-makers" [16]. While there is growing recognition that societal impacts need to be considered in adaptation frameworks, relatively little has been done to accomplish this integration.

Using a systems-level analysis focused on the service provided allows transportation decision makers to understand the relative significance of climate risk to different segments of the transportation network, based on the consequences of potential disruption to that segment on overall mobility and access. Assessing climate vulnerability from a systems perspective helps managers identify not only how the asphalt and signage of a road segment may be damaged by climate change, but - far more importantly-how significant that damage would be to the traveling public.

The sheer complexity of taking a systems approach requires an understanding of what is critical to a metropolitan 
region. Transportation managers need to target the facilities that are most vital to the system when allocating time and funds to adaptation measures. Such a "criticality" assessment was done as part of the second phase of the Gulf Coast Study [17] but is not yet routinely conducted. Criteria to assess criticality may include factors such as volume of passenger travel; critical access to key services, such as health care and schools; essential routes for emergency evacuation and first responders; and key routes for goods movement and commerce. Further, managers need to consider the degree of redundancy in a system: Do residents have multiple ways to reach a particular hospital? Can goods be transported by rail when a road is out of service? Ideally, the criteria for considering the relative priority of different assets will reflect the values and priorities of the region affected. Understanding the most critical components of the overall transportation network helps managers focus on shoring up the most important "weak links" in the system.

Perhaps even more significant, emerging approaches to vulnerability assessment recognize that the most importantand costly - effects of climate change impacts on transportation may not be the direct, physical damage or disruption that occurs to transportation infrastructure. Wilbanks et al., discuss three tiers of effects that need to be considered to comprehend the full scope of climate impacts on infrastructure services: "1) direct impacts on citizens and businesses, 2) impacts on service providers and business-to-business activities, and finally 3 ) regional or even national impacts" [18]. As described by Kirshen in an analysis of climate impacts on infrastructure in Boston, impacts on one sector of the economy can have ripple effects across multiple systems [19]. The effect of "cascading impacts" on other infrastructure, health and safety, and productivity can rapidly escalate the level of damage. This is particularly true in densely populated urban areas that depend on complex and interconnected systems of infrastructure, commerce, and community life. Even further, as economies become increasingly dependent on global resources and markets, the impact of climate events in one region can have direct repercussions in countries around the world $[18,20]$. Current analytical frameworks should be expanded to include these impacts.

\section{Adaptation Planning and Analysis}

The state of practice in transportation adaptation is developing, not through the scientific literature, but through on-theground activities at transportation agencies. Therefore, the actual state of practice is much more advanced than an initial literature review may reveal. Individual transportation agencies throughout the United States are indeed taking action to adapt to changes in extreme weather events and climate in each stage of transportation decision-making, from planning and siting through design and construction to operation and management. But these actions are rarely acknowledged as adaptation activities.

\section{Design and Siting}

Transportation agencies are recognizing the need to incorporate climate change adaptation into infrastructure design [21]. Indeed, most managers initially assume that adaptation measures require a "hard" engineering response. But analytic, financial, and institutional barriers have slowed the incorporation of climate change factors into facility design. As a result, most changes to asset design to date have concentrated on structures that are being rebuilt after being destroyed during extreme weather events. In this setting - where immediate decisions are required-political leadership, planners, and engineers can more readily justify changes to design that will make infrastructure stronger. For example, the US 90 Bridge over St. Louis Bay in Mississippi, which was destroyed after Hurricane Katrina, was rebuilt higher and more resistant to storm surge than the original structure.

In contrast, for routine capital investments, transportation agencies have not yet developed standardized approaches for incorporating climate science into engineering, particularly for new assets. Determining how to do this effectively is a primary frontier in adapting transportation systems to climate change. Additional communication between transportation engineers and climate scientists is necessary before projected climate conditions can be fully integrated into design decisions. Identifying potential sea level rise and providing specific guidance on the levels, which must be considered in infrastructure development, as has been done by California [22•], is a major step, yet just the first of the necessary actions required. Since sea level rise will act synergistically with storm surge and wave action to increase flooding and damage potential, design standards for coastal infrastructure ultimately should incorporate the combined risk of these climate stresses. Similarly, tropical storm intensification, another likely impact of climate change, raises the potential for higher sustained winds [23] and more damaging storm surge. Are the current standards adequate to protect not only transportation infrastructure, but the ancillary structures for signage, drainage, and communications on which service also depends? A forthcoming report from the Second Phase of the Gulf Coast Study identifies some of the trade-offs among adaptation options for transportation infrastructure in Mobile, Alabama [24]. But the next step, as called for by Engineers Canada is that, "Bodies responsible for engineering codes, standards and work practices should consider climate change as an additional factor in regular reviews to establish or change codes, standards and work practices" [25]. Inherent in their approach is the need for an ongoing process to review and update codes to better 
reflect the changing climate as conditions evolve and climate models are further refined.

An equally important need is to incorporate potential climate scenarios into the siting of transportation facilities: Locations for coastal highway alignments that may be acceptable assuming historic environmental conditions may prove to be too vulnerable under future conditions; airport runways, many of which are located very near water bodies, may be at risk of inundation under sea level rise. Until transportation agencies incorporate potential future climate stress into location choices for facilities, they run the risk of investing in facilities that will not withstand the test of time.

\section{Operations and Maintenance}

While adaptation strategies involving changes to design and siting typically require lengthy decision processes - and often significant cost - operation and maintenance (O\&M) strategies can be implemented relatively quickly. Transportation agencies regularly review and revise their O\&M procedures to ensure they can provide safe and reliable service. As agencies are experiencing an increasing number of extreme events and subtle changes in climate, they are revising their O\&M practices in real time. For example, Michigan DOT has changed how they prepare for snow in response to changes in Lake Effect snow patterns by changing the materials used, the number of employees assigned to weather response, and shift timing [26]. Alabama DOT has also reported changing O\&M practices; for example, they are changing the kinds of equipment used to make the agency's O\&M units more flexible in responding to different types of events, and they are increasingly coordinating with other organizations.

O\&M opportunities are being recognized as some of the "low hanging fruit" of adaptation, since these practices are more easily adopted and do not require the capital investments and lead time of other longer-range adaptation strategies such as elevating infrastructure. However, reacting to changes as they happen exclusively through O\&M will not likely be a sustainable way for organizations to adapt to climate change over decades. As discussed throughout this paper, the analytic frontiers in adaptation focus on how to most effectively integrate climate information and knowledge of an uncertain future into all aspects of transportation decision-making.

\section{Evaluation of Adaptation Options}

As transportation practitioners expand their understanding of the range of adaptation options that may be appropriateincluding, but not limited to, "hard" engineering responses - the challenge of evaluating these options becomes more complex. In fact, even assessing the relative costs of different adaptation measures is challenging. As noted in Sussman et al. (2013), there is scant literature on the costs of adaptation, and much of it is speculative because bottom-up evaluation studies of adaptation options are largely lacking [27•]. Sussman and her co-authors explore the state of knowledge regarding the national costs of adaptation in the United States. They find that "adaptation cost could be as high as tens or hundreds of billions of dollars per year by the middle of this century," while noting the numerous areas of analysis that need to be pursued to develop more robust quantification of the full costs - and benefits - of both climate impacts and adaptation measures.

Serious assessments are crucially needed of the costs and benefits of specific measures at the asset or metropolitan level that will provide more robust and resilient service in the face of climate change. Risk management needs to be married with engineering economics because no one will write a blank check for unproven adaptation measures, especially when the costs are high. There are some examples of work to better quantify costs and benefits. Venner and Zamurs (2012) focus on specific direct costs of particular adaptation measures, such as maintenance approaches [28 ${ }^{\bullet}$. Massachusetts DOT is evaluating the costs and benefits of different adaptation strategies for its Central Artery system in Boston. More work is needed. What are the costs of inaction against which adaptation measures should be compared? When does the return on investment warrant significant adaptation? Toward this latter question, strategies have been suggested to schedule adaptation improvements opportunistically with other capital improvements to keep costs down [18].

Closely tied to the costs of adaptation is the effectiveness of such measures. True evaluations of effectiveness will be a very long time coming given the imprecision in the timing and intensity of many climate impacts, and the longevity of the transportation infrastructure. However, some indication of the reduced risk to transportation systems is critical. Some studies exist not in the scientific literature but rather in individual engineering and design studies as assets are constructed or improved. Others are notable as well, particularly in green infrastructure, where reductions in wave energy due to mangroves, for example, have been estimated [29] and provide a measure of the effectiveness of maintaining such natural protection systems. But engineers and planners still wrestle with the relevant question of "how much resilience and at what cost?"

While facility-specific costs and effectiveness are challenging to evaluate, even more difficult to measure are the broader societal and environmental costs and benefits of adaptation actions. How can indirect and cumulative effects be valued? How can broader effects on economic prosperity, public safety, and ecological health be gauged? Ignoring the more systemic effects of different adaptation strategies can result in underestimating the value of some adaptation approaches, and in missed opportunities to enhance communities and regions. Tackling these more complex analyses is a challenging but 
necessary step if we are to develop truly resilient transportation systems that contribute to sustainable communities over decades.

\section{Adaptive Management}

Vulnerability assessment and adaptation are not one-time activities, but rather continuous processes of integrating new climate information, system objectives, and infrastructure conditions to develop and maintain a safe and effective transportation system that is able to meet changing conditions. This process - called adaptive management-is similar to existing planning and management practices in transportation, but as it relates to climate change, it is a relatively new concept. Yet the increasing focus of transportation professionals on performance-based management and asset management approaches provide an ideal platform for incorporating adaptive management concepts into transportation decisions.

\section{Asset Management}

Transportation Asset Management (TAM) is a strategy to facilitate operations that also provides several opportunities for managing climate-related and weather-related risks $[30 \bullet, 31]$. Asset management systems provide one of the most tangible ways for transportation agencies to incorporate climate risk into decision-making, since measures of climate risk can be incorporated in these systems alongside the numerous other factors that contribute to decisions, such as remaining service life, condition, usage, criticality, and others. This "mainstreaming" approach to climate assessment and adaptation - through which climate stress becomes one of multiple factors that inform decisions - can help ensure that transportation decisions are more likely to support long-term transportation and societal objectives.

For example, agencies such as the New York State DOT use asset management systems to record damages and costs associated with extreme weather [32]. Agencies can also use these systems to add flags for assets that are repeatedly damaged from weather events or to note vulnerability as determined through a vulnerability assessment. Asset management is increasingly being recognized as a best practice for improving transportation resilience; however, implementation as it relates to EWE's and climate change by transportation agencies is still in early stages.

Great strides have been made across the globe to introduce asset management systems as an overarching framework for transportation decision making[33-36], but extreme weather events both now and in the future pose mounting difficulties that still need to be addressed [31]. Planning for EWEs in transportation has always been difficult, and the prospect of more frequent or severe EWEs heightens the challenge.
Transportation agencies struggle with decisions about the level of resiliency that a transportation system can achieve in the face of severe storms, with concurrent infrastructure damage and flooding. Maintaining service versus protecting assets is a critical trade-off [37] and when to shut the system down becomes a paramount concern.

TAM as a framework for integrated decision making is intended to make these trade-offs explicit. But how can goals and objectives about service delivery under EWEs be determined? The uniqueness of storm events and other EWEs demands a deeper understanding of their disruptive capacity that will certainly require concerted study and data collection over the coming years.

The changing climate- which is expected to increase tropical storm intensity and may increase flooding events in some areas - is a further complication to incorporating EWEs into a TAM framework. Overblown political discussions about climate change uncertainties have muddied the issues involved, confusing arguments about a clear "signal" about the direction of future changes with the "precision" of future climate impacts. Nonetheless, the latter is still of critical concern to infrastructure managers and engineers. To what specific tolerances should infrastructure be built? At what point are thresholds exceeded and service can no longer be provided? Transportation agencies need to answer these questions before climate change can be fully incorporated into TAM goals and objectives. Processes for setting design standards [38] have typically served to answer these questions, but with climate change, the past is not a good indicator of the future, and the standards previously set must be reexamined. While TAM presents a significant step forward as an integrated decision framework, the full inclusion of EWEs and climate change poses substantial challenges.

\section{Conclusion}

The state of practice in vulnerability assessment and adaptation planning is rapidly evolving in the transportation sector, with more progress achieved, generally speaking, in assessing vulnerability than in taking adaptation action. Many advances have been realized through both basic and applied research, experimental approaches by practitioners, and enhanced collaboration of climate, environmental and transportation professionals. As a result, analytical frameworks have been developed, and the risks of climate change to transportation infrastructure and services are much better understood. There is also a growing appreciation of how climate risks can be assessed, monitored, and addressed. Agencies are now transitioning from assessing vulnerabilities to addressing vulnerabilities. They are beginning to implement adaptation strategies and monitor their effectiveness. As they begin to do so, the field faces several frontiers that will shape the future state 
of practice in transportation adaptation and point to new questions for the research community.

Climate challenges must be better integrated as a core consideration for the natural and built environments and for society as a whole. As climate stressors are realized through the natural environment and impact the built environment, the interaction between ecological systems and structures becomes even more complex. As the natural and built environments are impacted, society is affected as well. Only by understanding this integrated and dynamic system can an appreciation of the true costs of climate change as well as the benefits of adaptation be realized. Research must play a key role in furthering the state of the art in climate impact assessment and adaptation planning.

\section{Compliance with Ethics Guidelines}

Conflict of Interest Michael J. Savonis, Joanne R. Potter, and Cassandra B. Snow are all employees of and consultants for ICF. ICF has clients at the local, state, national, and international levels in both the public and private sector.

Michael J. Savonis's employer has received honoraria and travel/ accommodation expenses from the Boston College Center for Corporate Citizenship for a speaking engagement on the business implications of climate change.

Joanne R. Potter has received honoraria and travel/accommodation expenses from the U.S. Department of State for a speaking engagement with Brazilian cities organized by the U.S. Consulate in Brazil.

Cassandra B. Snow declares no conflicts of interest.

Human and Animal Rights and Informed Consent This article does not contain any studies with human or animal subjects performed by any of the authors.

\section{References}

Papers of particular interest, published recently, have been highlighted as:

- of importance

1. GCRP. Global climate change impacts in the United States. Washington: US Global Change Research Program; 2009.

2. Committee on Climate Change and U.S. Transportation, National Research Council. Potential Impacts of Climate Change on U.S. Transportation: Special Report 290. Transportation Research Board. March 2008.

3. CCSP. In: Savonis MJ, Burkett VR, Potter JR, editors. Impacts of climate change and variability on transportation systems and infrastructure: gulf coast study, phase I. A report by the U.S. Climate change science program and the subcommittee on global change research. Washington: Department of Transportation; 2008. 445 pp.

4. Transportation Research Board (TRB). "Adapting transportation to the impacts of climate change: state of the practice 2011". Transportation research E-Circular No. 152. Available at $<\mathrm{http}: / /$ onlinepubs.trb.org/onlinepubs/circulars/ec152.pdf> 2011.

5. Zimmerman R, Faris C. "Infrastructure impacts and adaptation challenges." In: Climate change adaptation in New York City: building a risk management response, New York City panel on climate change 2010 report. Rosenzweig C, Solecki W, editors. Annals of the New York Academy of Sciences. 2010;1196:63-8.

6. Stenek V. Climate risk and business ports: terminal Marítimo Muelles el Bosque. Prepared by the International Finance Corporation. Available at $<\mathrm{http}$ ://www-wds.worldbank.org/ servlet $/ \mathrm{main}$ ? $\mathrm{menuPK}=64187510 \&$ page $\mathrm{PK}=64193027 \& \mathrm{piPK}=$ $64187937 \&$ theSite $\mathrm{PK}=523679 \&$ entity ID $=000386194$ 201106210143192011.

7. FTA. Flooded bus barns and buckled rails: public transportation and climate change adaptation. FTA report No. 0001. U.S. Department of Transportation, Federal Transit Administration (FTA), Office of Budget and Policy. 2011. Thorough compilation of vulnerability assessment and adaptation strategies, specifically for transit agencies.

8. Dobney K, Baker CJ, Chapman L, Quinn AD. The future cost to the United Kingdom's railway network of heat-related delays and buckles caused by the predicted increase in high summer temperatures owing to climate change. J Rail Rapid Transit. 2010;224(F1):25-34.

9. Edinburgh Airport. Climate Change Adaptation Plan for Edinburgh Airport. 2011.

10. UNCTAD. Maritime transport and the climate change challenge. United Nations Conference on Trade and Development (UNCTAD). 2012.

11. Posey J. "Climate change impacts on transportation in the Midwest". In: U.S. national climate assessment midwest technical input report. [Winkler J, Andresen J, Hatfield J, Bidwell D, Brown D, coordinators]. 2012.

12. Rowan E, Evans C, Riley-Gilbert M, Hyman R, Kafalenos R, Beucler B, et al. Assessing the sensitivity of transportation assets to extreme weather events and climate change. Transp Res Rec: J Transp Res Board. 2013;2326:16-23.

13. Dobbins J, Abkowitz M. Improved methods for guiding climateinduced transportation infrastructure adaptation decisions. Vanderbilt Center for Transportation Research (VECTOR). Ongoing.

14. U.S. DOT. Screening for vulnerability. Impacts of climate change and variability on transportation systems and infrastructure, the gulf coast study, phase 2. Prepared by ICF International for the U.S. Department of Transportation Center for Climate Change and Environmental Forecasting. Unpublished.

15. Parry ML, Canziani OF, Palutikof JP, van der Linden PJ, Hanson $\mathrm{CE}$, editors. Contribution of working group II to the fourth assessment report of the intergovernmental panel on climate change. Cambridge: Cambridge University Press; 2007.

16. U.S. Department of Energy. Climate change and energy supply and use: technical report to the U.S. Department of Energy in support of the National Climate, Assessment. 2012.

17. FHWA. Assessing Criticality in transportation adaptation planning. Prepared by ICF International. FHWA-HEP-11-034. U.S. Department of Transportation, Federal Highway Administration (FHWA). 2011.

18. U.S. DOE. Climate change and energy supply and use: technical report to the U.S. Department of Energy (DOE) in support of the National Climate, Assessment. 2012.

19. Kirshen P, Ruth M, Anderson W. Interdependencies of urban climate change impacts and adaptation strategies: a case study of Metropolitan Boston USA. Clim Chang. 2008;86(1-2):105-22.

20. Becker AH, Acciaro M, Asariotis R, Cabrera E, Cretegny L, Crist P, et al. A note on climate change adaptation for seaports: a challenge for global ports, a challenge for global society. Clim Chang. 2013;120(4):683-95.

21. Meyer MD. Design standards for U.S. transportation infrastructure: the implications of climate change. Transportation Research Board of the National Academies. 2006.

22. Caltrans. Guidance on incorporating sea level rise. California Department of Transportation (Caltrans). 2011. Cutting-edge 
example of a state DOT issuing specific guidance about incorporating sea level rise into planning.

23. Typhoon Haiyan, which hit the Philippine coast in November 2013, was the fourth most intense storm as measured by maximum sustained wind speed, with sustained winds of 190 to $195 \mathrm{mph}$ at landfall, far above the Category 5 starting point of $157 \mathrm{mph}$ on the Saffir Simpson scale. Source: Fischetti M. Was Typhoon Haiyan a record storm? Scientific American. 2013.

24. U.S. DOT. Engineering analysis and assessment. Impacts of climate change and variability on transportation systems and infrastructure, the gulf coast study, phase 2. Prepared by Parsons Brinckerhoff and ICF International for the U.S. Department of Transportation Center for Climate Change and Environmental Forecasting. Unpublished.

25. Engineers Canada. Climate change: the profession's position. Engineers Canada. 2013.

26. Meyer MD, Rowan E, Snow C, Choate A. Impacts of extreme weather on transportation National symposium summary. American Association of State Highway and Transportation Officials. 2013.

27. Sussman F, Krishnan N, Maher K, Miller R, Mack C, Stewart P, et al. Climate change adaptation cost in the US: what do we know? Clim Pol. 2014;14(2):242-82. Literature review covering the state of knowledge about costs of adaptation. It includes analysis of limitations and recommended steps for improving understanding of adaptation costs.

28. Venner M, Zamurs J. Increased maintenance costs of extreme weather events: preparing for climate change adaptation. Transp Res Rec: J Transp Res Board. 2012;2292:20-8. Highlights an important element of adaptation: understanding the costs of not adapting. It covers case studies of extreme weather events as a starting point for assessing the potential costs of climate change.

29. Schmitt K, Albers T, Pham TT, Dinh SC. Site-specific and integrated adaptation to climate change in the coastal mangrove zone of Soc Trang Province, Viet Nam. J Coast Conserv. 2013;17(3):545-58.
30. FHWA. Risk-based Transportation Asset Management: Building resilience into transportation assets. U.S. Department of Transportation, Federal Highway Administration (FHWA). FHWA-HIF-13-018. 2013. This is a guidance document on how to use Transportation Asset Management to manage risks. It includes discussion of using TAM to manage risks from climate change and extreme weather events.

31. Meyer MD, Rowan EP, Savonis MJ, Choate A. Integrating extreme weather risk into Transportation Asset Management. American Association of State Highway and Transportation Officials. 2012.

32. FHWA. Risk-based transportation asset management: building resilience into transportation assets. U.S. Department of Transportation, Federal Highway Administration (FHWA). FHWA-HIF-13-018. 2013.

33. FHWA. Transportation Asset Management in Australia, Canada, England, and New Zealand. U.S. Department of Transportation, Federal Highway Administration (FHWA). FHWA-PL-05-019. 2005.

34. NZ Transport Agency. State highway asset management plan. New Zealand Transport Agency. 2011.

35. FHWA. 2012 Transportation asset management peer exchange. U.S. Department of Transportation, Federal Highway Administration (FHWA). FHWA-HIF-13-069. 2013.

36. FHWA. Beyond the short term: transportation asset management for long-term sustainability, accountability and performance. U.S. Department of Transportation, Federal Highway Administration (FHWA). FHWA-HIF-10-009. 2012.

37. MTA. MTA prepares for Hurricane Sandy. Metropolitan Transportation Authority, October 26, 2012. Available at $<$ http:// new.mta.info/press-release/mta-headquarters/mta-prepareshurricane-sandy> 2012.

38. AASHTO. A policy on geometric design of highways and streets. 6th edn. American Association of State Highway and Transportation Officials. 2011. 